\title{
0 estágio supervisionado nos cursos de licenciatura em música: discutindo a aprendizagem colaborativa para a formação docente na contemporaneidade
}

Supervised internship in music degree courses: discussing collaborative learning for contemporary teacher education

Francine Kemmer Cernev

Universidade de Brasillia - UnB

francine@cernev.com.br 


\section{Resumo}

Este artigo tem por objetivo discutir sobre a formação de professores a partir das experiências desenvolvidas por meio do estágio supervisionado em música durante o período de ensino remoto emergencial. $O$ referencial teórico foi constituído a partir dos seguintes eixos: tecnologias digitais e mídias sociais, aprendizagem colaborativa e formação para a docência em música. A metodologia utilizada foi a pesquisa ação. Para tanto, os licenciandos foram instigados a desenvolver uma proposta de estágio que culminou na produção colaborativa e aplicação de um material pedagógico-musical virtual no contexto da educação básica. Foram estabelecidas reflexões sobre o papel do estágio supervisionado em novos contextos e cenários a partir da realização e implementação desta produção, bem como discussões sobre suas implicações para a profissionalização de licenciandos. As impressões reveladas pontuam positivamente para a construção colaborativa de propostas educacionais pautadas na identificação, elaboração, realização, atuação e reflexão, fazendo parte consubstancial para a compreensão da formação da docência em música na contemporaneidade.

Palavras-chave: aprendizagem colaborativa; formação docente; estágio supervisionado em música; ensino remoto emergencial.

\section{Abstract}

This article aims to discuss the training of teachers from experiences developed through supervised internship in music during the period of emergency remote teaching. The theoretical framework was constituted from the following themes: digital technologies and social media, collaborative learning and training for music teaching. The methodology used was action research. The undergraduates were encouraged to develop an internship proposal that culminated in the collaborative production and application of a virtual musical-pedagogical material in at school. Reflections were established on the role of the supervised internship in new contexts and scenarios from the realization and implementation of this material, as well discuss the implications for the professionalization of these undergraduates. The impressions revealed score positively for the collaborative construction of educational proposals based on the identification, elaboration, realization, performance and reflection, being an essential part for the understanding of the formation of music teaching in contemporaneity.

Keywords: collaborative learning; teacher training; supervised internship in music; emergency remote teaching. 


\section{O Estágio supervisionado em Música na Universidade de Brasília}

A prática de ensino nos cursos de licenciatura é considerada um pilar em programas de formação de professores, sendo uma premissa necessária para a profissionalização docente (ABDULLAH; SULONG; RAHIM, 2020). Em muitos cursos de licenciatura, as discussões sobre a formação de professores estão voltadas à qualificação de profissionais autônomos, criativos e com consciência crítica para atender às demandas emergentes (De BRUIN, 2019; BURWELL, 2012; CREECH; GAUNT, 2012; SHIOZAWA; PROTÁSIO, 2017).

No ensino superior, mais precisamente nos cursos de licenciatura em música da Universidade de Brasília - cujo objetivo é a formação de professores para atuar na educação básica (mas também em outras esferas do cenário educativo) -, o estágio supervisionado se configura em um exercício da aprendizagem da docência (GAULKE, 2013). Santana (2020, p. 54-55) apresenta sua perspectiva enquanto licencianda nesse cenário, ao resignificar sua própria formação, explicando que o estágio supervisionado em música é um momento que possibilita "pensar o ensino de música em um contexto específico e observar a importância da convivência no ambiente escolar". Além disso, destaca a necessidade de "buscar aprender constantemente e se atualizar com tecnologias acessíveis" e apresenta algumas reflexões a partir da "multiplicidade de relações e sentidos que o sujeito pode estabelecer durante a vida com a música".

Allsopp et al. (2006) acreditam que a experiência de ensino dá aos professores em formação oportunidades de aplicar o que aprenderam na universidade dentro do contexto de uma sala de aula. Para tanto, focalizam a necessidade do respeito pelo papel do professor no desenvolvimento educativo e aponta direcionamentos para o próprio desenvolvimento profissional por meio da observação colaborativa, pesquisa e investigação de sua prática docente. Algumas reflexões emergem nesse contexto, como: enquanto professores e orientadores de estágio docente, estamos formando professores de música para formar novos sujeitos para qual sociedade? Quais aspectos são fundamentais para o posicionamento dos estagiários frente às demandas emergentes que surgem no campo de atuação? E como se (re)configura a docência em música em novos cenários e contextos, como o gerado pelo ensino remoto emergencial?

Ao refletir sobre os objetivos dos cursos de formação inicial de professores, percebemos a necessidade de desenvolvermos uma epistemologia da práxis profissional vinculada à construção e reconstrução de uma possibilidade de ensino a partir de um campo empírico (CURADO SILVA, 2017). Neste caso, os saberes mobilizados pelos estagiários de música em situação concreta da prática pedagógica são considerados como pontos cruciais de reflexão, visando auxiliar o desenvolvimento profissional do aluno em congruência com a sociedade e comunidade que habita (GARVEY; STOKES; MEGGINSON, 2009). Isto implica discutir a formação de professores num processo contínuo de análise, atuação e reflexão para, na e pós ação como base para sua formação (TARDIF, 2013; ALTET, 2001). 
A partir do momento em que todas as instituições de ensino tiveram que se adequar a um ensino remoto e emergencial ${ }^{2}$, surgiu nos nossos estudos e encontros docentes os seguintes questionamentos: é possível a oferta do estágio supervisionado em música de forma remota priorizando a vivência no campo de estágio no contexto da educação básica? Como a Universidade pode articular propostas educacionais que contemplem a formação dos estudantes de música associadas às novas demandas de profissionalização que são geradas nesse contexto? Como podemos propiciar em nossos cursos de formação de professores a capacidade dos nossos alunos se tornarem profissionais nas condições trazidas pelo ensino remoto emergencial? Quais significados e aprendizagens serão gerados e que farão parte da futura docência deste licenciado em música?

Este estudo teve como objetivo discutir a formação de professores de música durante o ensino remoto emergencial (ERE) a partir da perspectiva dos licenciandos. Visando refletir e se debruçar sobre estas questões, busquei na colaboração uma proposta de ensino com o propósito de desenvolver metodologias e estratégias de aprendizagem, didática e produção de materiais didáticos a partir de conteúdos musicais voltados ao contexto da educação básica. A partir da construção colaborativa e implementação em uma escola de educação básica do Distrito Federal, os licenciandos refletiram sobre o papel do estágio supervisionado em novos contextos e cenários, bem como suas implicações para a formação docente a partir do uso de metodologias ativas em educação. Compreender e problematizar o uso das tecnologias digitais e das mídias sociais como possibilidades para a atuação profissional também se fez relevante no momento atual, pois, além de próximas, estão intimamente ligadas às manifestações culturais de nossa sociedade (CERNEV, 2017a).

A expressão "aprendizagem colaborativa" tem sido utilizada em vários âmbitos das ciências humanas, tendo como premissa o desenvolvimento de um trabalho conjunto que visa um objetivo comum. No contexto educativo, aprendizagem colaborativa se pauta num processo de diálogo ativo e expositivo de ideias entre os participantes. Torres e Irala (2014) explicam as ações envolvidas nesta aprendizagem: participação ativa do aluno no processo de aprendizagem; interatividade dos diversos atores que atuam no processo; estimulação dos processos de comunicação e expressão; aceitação das diversidades e diferenças; desenvolvimento de autonomia dos alunos e mediação do professor. Os fundamentos teóricos partem do pressuposto que o conhecimento é construído socialmente mediado pela participação e interação entre alunos e professores. Como pressuposto metodológico, aborda a interdependência e a formação do processo educativo pautado na experimentação e no protagonismo do aluno, principalmente mediado pelas tecnologias de informação e comunicação (CERNEV, 2018; TORRES; LOPES; CAMARGO, 2021).

\footnotetext{
2 Ensino remoto emergencial trata-se de um ensino ocorrido a partir da disseminação do vírus SARS-COV 2 (COVID-19). Remoto, pois as aulas presenciais foram substituídas pela mediação tecnológica e emergencial pois foi criada sem um estudo estrutural pedagógico, apenas a fim de criar mecanismos para que os planejamentos letivos continuassem em funcionamento.
} 


\section{Percurso Metodológico}

Esta pesquisa foi desenvolvida no âmbito da disciplina de Estágio Supervisionado em Música - ESM, na Universidade de Brasília - UnB, no formato de pesquisa ação. A pesquisa ação foi escolhida como caminho metodológico por constituir o ambiente natural (campo investigativo) com finalidade de gerar dados sobre os processos de ensino e aprendizagem escolar. De acordo com Kemis e McTaggart (2005), envolve tanto uma investigação autoreflexiva e coletiva de maneira a melhorar a racionalidade das próprias práticas sociais e educacionais quanto contribui com o entendimento dessas práticas e das situações onde elas se configuram. Também, Morin (2004) destaca que ela propicia mudança pela transformação recíproca da ação e do discurso.

Participaram do estudo 11 estagiários do curso de licenciatura em música da UnB, a professora investigadora/orientadora e o professor do campo de estágio. Os 11 estagiários que compuseram essa pesquisa ação estavam em distintos níveis de estágio (sendo 1 no ESM1; 1 no ESM2 e 9 no ESM3). Na Universidade de Brasília, temos atuado com estágios multisseriais em que os alunos escolhem o grupo a partir de temáticas específicas de seus professores orientadores. Tenho desenvolvido nos meus grupos de estágio temáticas voltadas ao uso das tecnologias de informação e comunicação (TIC) pensando metodologicamente na aprendizagem musical colaborativa (CERNEV, 2018).

Esta pesquisa ocorreu com um grupo de estagiários do primeiro semestre letivo de 2020, ministrado entre os meses de agosto e dezembro deste mesmo ano ${ }^{3}$. Como instrumento de coleta de dados foram utilizados os relatórios semanais (diários de campo realizados em formato de crônicas), diálogos no processo de elaboração do material didático colaborativo por meio das gravações das reuniões pedagógicas, conversas entre os professores pelas redes sociais (profa. orientadora e prof. do campo de estágio) e relatórios finais produzidos por cada estudante no formato de memorial formativo.

Para a ação docente, foi desenvolvido um material didático virtual, construído colaborativamente e divulgado para os alunos do 6으 a $9 \circ$ ano do Ensino Fundamental II por meio do ambiente virtual de aprendizagem (google classroom) disponibilizado pela Secretaria de Educação do Distrito Federal (SEEDF). A partir das reflexões sobre as possibilidades de estágio durante o período de isolamento social bem como as ofertas de campo de atuação, foi escolhida propositalmente uma escola rural, distante geograficamente da Universidade de Brasília e que, em circunstâncias presenciais, dificilmente seria contemplada e escolhida pelos estagiários para atuação por ser de difícil acesso e mobilidade junto ao DF. A proposição de estágio com este campo emergiu pela parceria anterior com o professor regente e foi escolhida pelos próprios estagiários que se empolgaram em dialogar com as experiências pessoais, sociais e culturais destes alunos.

3 Por conta do contexto pandêmico, as atividades educacionais em todo o DF foram suspensas em 14/03/2020 (quatro dias após o início do calendário letivo). A Universidade de Brasília suspendeu suas atividades letivas e promoveu uma série de alterações estruturais e capacitação de seu corpo docente, adequando à nova realidade educacional e retornando com suas atividades totalmente voltadas ao ERE no início de agosto. Portanto, apesar de ser no segundo semestre do ano, são alunos pertencentes ao primeiro semestre letivo. 
O projeto culminou na produção coletiva de uma série de podcasts sobre diversos assuntos que permeiam a linguagem musical e pautadas nas competências e habilidades trazidas na Base Nacional Comum Curricular (BNCC) para a disciplina de Arte, vídeos de apreciação musical com apresentação de instrumentos e arranjos coletivos, desafios, jogos e curiosidades musicais, além da atuação de cada estagiário no espaço virtual de aprendizagem do colégio. Todo o material audiovisual, identidade visual e design gráfico foi elaborado, produzido, masterizado, editado e postado pelos próprios estagiários. Para avaliação e feedback sobre a aprendizagem gerada junto aos alunos do Colégio de Ensino Fundamental Jataí - CEF Jataí, desenvolvemos enquetes disponibilizadas virtualmente (ou entregues para alunos que preferiam ou necessitavam no formato impresso).

Os episódios contaram com diferentes autores em sua produção e produzidos em diferentes formatos a fim de contemplar a diversidade de ideias, habilidades, competências, estilos de aprendizagem e multiplicidades de opções para a assimilação destes conteúdos tanto por parte dos estagiários, como por parte dos alunos do CEF Jataí. A escolha plural teve como objetivo propiciar estratégias de ensino diferentes para diversificar a apreensão auditiva dos alunos. O resultado desta produção gerou episódios em formato jornalístico, entrevistas, diálogos entre os estagiários e também documentários. Os temas vieram a partir do planejamento do professor do campo de estágio amalgamado com as ideias e propostas trazidas pelos estagiários.

Ainda, visando aproximar os alunos para esta nova forma de aprender música e integrando o uso das tecnologias estabelecidas na BNCC, optamos por compartilhar todo o material didático em quatro redes sociais mais populares na atualidade: YouTube, Instagram, Facebook e Spotfy ${ }^{4}$, acessíveis a esta faixa etária de estudantes. A ideia foi que os alunos pudessem interagir em ambientes que eles têm interesse no seu cotidiano, criando uma aprendizagem para além da sala de aula virtual. Especificamente, as mídias sociais (surgidas com a ascensão da web 2.0), tem sido ferramentas importantes de interação entre os alunos, criando não apenas um local para postagem de conteúdo, mas um espaço para exploração, criação, discussão e reflexão de materiais pedagógico-musicais, ampliando espaços para além das barreiras geográficas.

Durante a realização, implementação, acompanhamento e avaliação das aprendizagens geradas por, para e na escola, os estagiários desenvolveram semanalmente seus diários de campo em formato de crônicas. A proposta era que eles não relatassem simplesmente a rotina gerada na escola (pelo espaço virtual de aprendizagem), mas que exercessem, por meio do exercício da escrita, reflexões, interações e discussões com uma linguagem literária diferenciada da utilizadas por eles até então. Assim, algumas crônicas foram realizadas em formato jornalístico; outras em prosa e versos; algumas em diálogos e debates e outras em fábulas. Ao final do semestre, cada estagiário desenvolveu um artigo relato de experiência sobre todo o seu processo de construção da docência, elaborado em formato de memorial formativo.

4 Para conhecer o material didático nas redes sociais, acesse: https://linktr.ee/musicanaescola. 


\title{
Reflexões sobre a formação docente a partir da produção colaborativa
}

No momento em que a sociedade educacional busca formas de atuar e ministrar suas aulas mediadas pelas plataformas digitais, existe a necessidade do envolvimento coletivo da Universidade para formar professores que possam aprender a lidar com essas tecnologias e usá-las de modo construtivo e problematizado. Tenho desenvolvido tais proposições ao longo da última década, gerando uma série de estudos (CERNEV 2013; 2015; 2017a; 2017b; 2018) que buscam discutir as potencialidades das TIC, mas ciente de seus limites mediante a estafa gerada pelo excesso de informações mediáticas que vivemos na atualidade. Esta foi a realidade também percebida por Ismael:

\begin{abstract}
Este ano atípico tem nos colocado à prova, nos levado a experimentar novas formas de agir, de nos relacionar com as pessoas, com o mundo. Aos professores e futuros profissionais da educação, ficou a custosa e desafiadora tarefa de pensar e repensar soluções aos problemas urgentes que confrontam a prática docente e a construção dos processos de ensino e aprendizagem.[...] Diferentemente do ensino presencial - não que seja sempre assim - no ensino remoto, a tecnologia não deve ficar reduzida apenas a uma espécie de suporte para acomodar um certo conteúdo. Não é apenas um apetrecho, pelo contrário, é ferramenta pedagógica capaz de produzir conhecimento, desencadear processos de ensino e aprendizagem de maneira reflexiva, crítica e prática. No estágio supervisionado, com a cuidadosa orientação da professora Francine, foi possível perceber essas nuances, compreender as possibilidades de expandir os significados, compreendendo a relevância e as potencialidades do mundo virtual para a educação musical (Ismael, memorial formativo).
\end{abstract}

Diante de um cenário novo causado pela covid-19, oportunidades precisaram ser criadas para conectar a prática pedagógica ao conhecimento teórico e tornar esse conhecimento conectado no contexto atual, concebendo essa construção da formação docente amparado à teoria, à prática e à necessidade do campo como um objeto de ação. Apesar de muitas pesquisas já incentivarem o uso das tecnologias no contexto da educação musical, (CERNEV 2018, SALES, ARALDI, BATISTA, 2021; JARDIM, MARINS, 2019), até então ela era pautada como recurso e ferramenta para o ensino na educação a distância ou como estratégias de aprendizagem para agregar valores em situações presenciais. $O$ ensino remoto emergencial alterou consideravelmente esta perspectiva, destacando a necessidade do uso das ferramentas tecnológicas em todos os momentos e para todos os estudantes e professores. Foi visível observar como alunos, professores e instituições de ensino não estavam preparados a este novo cenário e se sentiram "perdidos" nesse processo. Neste contexto, Cernev (2018) cita:

O interesse dos alunos em desenvolver um trabalho que, por utilizar as tecnologias em sala de aula, é muitas vezes considerado "novo" para sua aprendizagem e, ao mesmo tempo, a dificuldade de professores tanto em utilizar as tecnologias digitais para as práticas musicais quanto em sair do foco central como o único responsável pela aprendizagem em sala de aula ressaltam a importância deste estudo e a reflexão sobre esta temática na área da educação musical (CERNEV, 2018, p. 34). 
Moran (2013, p. 63) já problematizava essa perspectiva trazida por Cernev sobre a existência de uma relação distanciada entre alunos e professores com as experiências tecnológicas, explicando a necessidade de mudanças profundas na concepção do ensino. Desta forma, o uso das TIC não podem ser simplesmente inseridas numa disciplina ou num contexto já existente sem uma mudança nos paradigmas educacionais; caso contrário, seu uso será apenas um "verniz de modernidade, sem mexer no essencial". Partindo desta perspectiva, mexemos nesse "essencial", deslocamos o papel central do professor como o único responsável pela aprendizagem em sala de aula e inserimos o protagonismo do aluno (CERNEV, 2015). A partir das escolhas, elaboração e reflexão da produção do material intitulado "Projeto Música na Escola: Artes no CEF Jataí", o estagiário Douglas reflete sobre sua aprendizagem nesse processo:

\begin{abstract}
As habilidades desenvolvidas no estágio que ocorreram de forma remota exigiu e ao mesmo tempo desenvolveu conhecimentos didáticos com o uso de podcast que é uma interação de áudio em que se aproxima do papel do rádio (que ocorria há anos atrás), mas que o ouvinte tem a possibilidade de escolher qual assunto ou temática ele deseja ter contato e acompanhar de acordo com a sua disponibilidade ou interesse por se tratar de um veículo assíncrono. Outras ferramentas que foram utilizadas na disciplina de estágio supervisionado em música além dos podcasts foram as redes sociais e para isso habilidades de edição de imagem, ângulo de captação de vídeo e outros elementos de tratamento de imagem foram necessários para tornar a aprendizagem dos alunos multidimensional. Conciliar as aulas online, se encontrar para gravar de forma remota e produzir o material em áudio e audiovisual exigiram a divisão da turma de forma que uma parte editasse, outra parte produzisse o conteúdo e ao mesmo tempo acompanhar as aulas do professor regente da disciplina de arte exigiu muita organização e comprometimento, pois as ferramentas utilizadas eram completamente novas para alguns estagiários (Douglas, memorial formativo).
\end{abstract}

Para que o projeto ocorresse, os estagiários foram instigados a diferentes desafios entendendo a docência como processo contínuo de aprendizagem e desenvolvimento profissional e humano. A colaboração foi essencial nas discussões sobre a formação docente e na mobilização de saberes necessários para este novo contexto. A aprendizagem colaborativa reconhece e respeita o interesse prévio de cada estudante, sua experiência e seu entendimento de mundo envolvendo a participação de todos no processo de construção do conhecimento. Além disso, incentiva autonomia e responsabilidade pela sua aprendizagem e do grupo. Com essa interação, os estudantes desenvolvem a capacidade de uma aprendizagem autorregulada na capacidade de preparar, facilitar e controlar a própria aprendizagem, proporcionar feedback e reflexões quanto aos seus próprios resultados. A proposição colaborativa para o desenvolvimento do projeto uniu e motivou os estagiários pois podiam compartilhar, ensinar e aprender sem a preocupação de serem responsáveis por todas as ações que envolvem uma produção didática. Mley reflete sobre suas percepções nesse contexto, mostrando a multiplicidade de habilidades necessárias para a colaboração:

Para a produção do projeto proposto pelos estagiários foi preciso organização para definir como seria produzido, quais recursos seriam utilizados e quem seria 
responsável por desempenhar funções específicas. O interessante de um trabaIho colaborativo é essa capacidade que ele tem de interação e de troca de conhecimentos. Embora os estagiários sejam do mesmo curso, ou seja, compartiIham da mesma área de conhecimento, eles possuem capacidades e habilidades diferentes. Essa troca de conhecimentos e informações, com base no respeito e empatia entre os pares é o combustível que alimenta uma equipe a conseguir alcançar seus objetivos (Mley, memorial formativo).

De fato, a possibilidade de partilhas, trocas e reflexões próprias da aprendizagem colaborativa desenvolvida nesse projeto foi fundamental para que estes estagiários pudessem articular saberes, experiências, responsabilidades e buscassem soluções conjuntas para discutir o estágio neste cenário de distanciamento social. Com a proposta de um objetivo comum, esse tipo de abordagem estimulou o pensamento crítico e racionalizado sobre o conhecimento, criando possibilidades de interação, negociação e resolução de problemas. Assim, a reprodução de conhecimento é rejeitada nesta abordagem, pois não se deve colocar o aluno como sujeito passivo nesse processo de ensino-aprendizagem (TORRES; LOPES; CAMARGO, 2021). Sob este aspecto, Honigsfeld e Nordmeyer (2020) relatam a necessidade de pensar propostas e estratégias de ensino adequadas ao momento atual, destacando a colaboração como importante mecanismo para os docentes:

Em vez de focar em salas de aula "remotas", "à distância" ou "virtuais", podemos mobilizar o ensino e a aprendizagem em casa como um ativo. É importante mudar a visão baseada no déficit do "desafio" de transpor a aprendizagem presencial para a aula online para uma visão baseada em ativos: encontrar novas e diferentes oportunidades no aprendizado em casa5 (HONIGSFELD; NORDMEYER, 2020, p. 49).

Mais importante ainda, é preciso pensar em estratégias de aprendizagem que atendam o interesse dos alunos e possibilitem maior interação e motivação para que eles se interessem pela aprendizagem, mesmo em situações de conflitos, como o ERE. Embora existam uma diversidade de recursos, ferramentas e pedagogias online, Biesta (2019) expressa sua preocupação para o ensino online para que não signifique "um retorno a formas mais tradicionais de ensino" (p. 55). Isso levanta questões sobre a crise que estamos enfrentando atualmente e como podemos (re)transformar estes campos com metodologias ativas que possam ser efetivamente entrelaçadas na formação dos professores de música.

Conceber o ensino de música utilizando pressupostos das metodologias ativas implica em estabelecer interrelações entre educação, cultura, sociedade, escola, buscando sempre atividades centradas no aluno (VALENTE, 2018). Desta forma, destaco para as possibilidades de transformações nas aulas de música, trazendo experiências vivas, significativas em relação ao ensino, à aprendizagem e ao próprio desenvolvimento e formação musical, diferentes das experiências de gerações anteriores. Pensar em ações

\footnotetext{
5 Rather than focusing on "remote" or "distance" or "virtual" classrooms, we can leverage teaching and learning from home as an asset. It is important to shift from a deficit-based view of the "challenge" of translating face-to-face instruction into an online classroom, to an asset-based view: finding new and different opportunities in home learning.
} 
formativas junto ao projeto "Música na Escola" foi importante não apenas para os alunos no CEF Jataí, mas na formação destes futuros professores pois oportunizou experiências pautadas na experimentação, design e aprendizagem maker propiciada pelas tecnologias digitais.

As tecnologias digitais são ferramentas que auxiliam a produção de materiais e produtos audiovisuais que antes eram destinados a gravadoras profissionais. $\mathrm{O}$ ato de ensinar $\mathrm{e}$ aprender são motivadores quando são convertidos em processos de pesquisa, questionamentos, criações e experimentações a partir da reflexão e partilhas colaborativas. De fato, as tecnologias digitais (e neste projeto priorizamos as gratuitas ${ }^{6}$ ) auxiliaram nesta construção, uma vez que permitiram a participação, a intervenção, a bidirecionalidade e a multiplicidade de conexões. Caio e Cibele discutem essa situação e refletem como a produção de cada podcast foi se delineando em sua aprendizagem formativa:

\begin{abstract}
Foi desafiador pensar que esse material poderia ensinar os alunos a distância e como que eu, professora poderia acrescentar esse projeto à minha formação. Percebi ao longo do semestre que não só eu mas os colegas no grupo da produção do podcast também puderam transformar o conhecimento para uma maneira mais didática de como ensinar, como mostrar que o conhecimento da música pode mudar a perspectiva da vida dos alunos (Cibele, memorial formativo).

O projeto foi tomando corpo e o resultado vinha me surpreendendo, principalmente por ser um trabalho colaborativo, onde os participantes apareceram nesse semestre, de forma randômica, cada um com suas habilidades, e tudo foi se encaixando. Uns com mais, outros com menos; uns que sabiam editar, outros que escreviam textos como ninguém e tinham muito a dizer; uns bastantes artísticos, outros bastante determinados. Eu não teria escolhido um time melhor que desenvolvesse esse projeto nessas condições em que vivemos esse semestre. Falo tão entusiasmadamente, pois, através do trabalho colaborativo, senti-me parte dessa engrenagem que movimenta o ensino de música (Caio, diário de campo).
\end{abstract}

As reflexões de Caio e Cibele mostram como uma proposta pautada em despertar as potencialidades de cada estudante são fundamentais para eles se sentirem parte do processo formativo. Para a reflexão do estágio supervisionado em música, a experiência de elaboração de um material didático no formato virtual foi extremamente relevante para discutirmos a formação docente dentro da realidade do ERE, refletindo, conhecendo e procurando potencialidades que despertassem vivências musicais na realidade proposta. A experiência vivenciada no projeto "Música na Escola", trouxe à tona habilidades individuais e coletivas dos alunos do ensino superior que podem atuar de acordo com seus interesses e conhecimentos adquirido num projeto colaborativo.

\footnotetext{
6 Para este projeto utilizamos para gravação o programa Discord, por permitir gravações simultâneas e download destes áudios em arquivos multipistas. Para edição e masterização priorizamos a utilização do programa Audacity, mas em alguns momentos os estagiários utilizaram para finalização softwares já familiarizados e que são integrados na compra de seus próprios equipamentos.
} 


\section{Reflexões para o futuro professor de música}

Moran já enfatizava que, "se ensinar dependesse só de tecnologias, já teríamos achado as melhores soluções há muito tempo" (MORAN, 2013, p. 12). As tecnologias são importantes, mas não resolvem todas as questões que envolvem a prática educativa. $A$ experiência é para cada indivíduo, singular e de alguma maneira impossível de ser repetida (BONDÍA, 2002). O processo de formação de professores de música, principalmente por conta do ERE culminou na necessidade de propormos estratégias tecnológicas e refletirmos nas ações pedagógicas para o ensino de música mediado pelo ciberespaço pois "esse tipo de experiência [leva] a pensar e ver que estou tendo a oportunidade de ser uma professora com um 'pé' na tecnologia, com novos caminhos para o conhecimento a ser compartilhado" (Cibele, memorial formativo).

Atuar na formação de futuros professores significa construir junto aos estagiários processos de ensino e aprendizagem que permitam aprender conteúdos específicos da linguagem musical e procedimentos didáticos inovadores que possam ser utilizados no exercício da docência. Organizar o projeto "Música na Escola" na perspectiva do ERE, integrando tecnologias, metodologias e estratégias pedagógicas, teve o intuito de promover a aprendizagem dos estagiários e pautar na identificação de dúvidas, discutindo a implicação destes materiais na formação profissional a partir das experiências pessoais, profissionais e formativas visando sempre a autonomia. Apesar das dificuldades geradas pelo medo e apreensão mediante uma situação pandêmica que vivenciamos logo no início do período de isolamentos social com essa experiência de estágio, os alunos se sentiram desafiados e motivados a pensar em seu papel para, com e na docência, relatando resultados positivos nesse processo:

Caro Leitor: este semestre me trouxe experiências incriveis; poder entender como a produção de um material didático me trouxe novas perspectivas enquanto profissional da música e ser professor. Pude entender que o mais importante na arte de lecionar e se tornar professor é analisar e entender cada circunstância para tomar a melhor decisão que ofereça aos seus alunos a melhor opção de ensino. Além disso, pude presenciar na prática sobre a importância do trabalho em grupo e o cumprimento dos prazos para o bom funcionamento da aprendizagem colaborativa e tudo ser entregue de acordo com os combinados (Samuel, diário de campo).

A experiência em produzir gravações, edições e masterizações totalmente de forma remota pelos próprios estagiários (a fim de resguardar a saúde de todos os envolvidos) resultou em uma experiência colaborativa única e eficaz. Gonzalez et al. (2020) analisaram o desempenho dos alunos universitários durante o período de ERE, encontrando melhorias no desempenho da aprendizagem em comparação com estudos anteriores realizados de forma presencial. Os autores destacaram o comprometimento e a colaboração como fatores fundamentais para esta conquista. Estas questões também foram evidenciadas pelos estagiários do projeto "Música na Escola", que assumiram a responsabilidade musical, pedagógica e técnica desta produção, cada um de acordo 
com suas habilidades, compartilhando as próprias experiências e saberes adquiridos nesse processo: "o estágio supervisionado em música foi o exemplo de reunir um grupo criativo que foi se tornando coeso por meio das diferentes habilidades dos estudantes da Universidade de Brasília: quem grava? quem edita? quem posta?" (Douglas, diário de campo). Da mesma forma, Luan reflete:

\begin{abstract}
A professora Francine fez um trabalho muito bom para nos organizar de forma a produzir os episódios dos podcasts de forma colaborativa, procurando valorizar as habilidades que cada estagiário já possuía. Eu, por exemplo, fiquei responsável mais pela edição dos áudios dos podcasts já que essa é uma habilidade que eu já trazia de antes da faculdade de música e fico feliz de poder ter exercitado e desenvolvê-la durante esse semestre. [...] esses processos foram importantes para reforçar certas habilidades, mas acredito que a maior influência positiva para a minha formação docente foi observar como a nossa orientadora conseguiu organizar 11 estagiários para trabalharem colaborativamente na construção do podcast e de conteúdos para outras redes sociais, principalmente o Instagram (Luan, memorial formativo).
\end{abstract}

A experiência do estágio na formação dos futuros professores também teve o intuito de agregar diferentes experiências e conhecimentos, associando a partilha do conhecimento específico como processos psicológicos e de aprendizagem, métodos e técnicas didáticas adequadas e as finalidades sociais e políticas da educação escolar (CURADO SILVA, 2017, p. 128). Não pode ser um momento burocrático da formação, mas sim um encontro entre Universidade e Escola, a fim de "dar oportunidade para o outro apropriar-se do conhecimento produzido socialmente; desvelar as contradições da realidade e, então, fazer valer seus direitos e buscar a transformação social". Apesar destas discussões, alguns alunos ainda têm essa visão burocrática do estágio, como uma meta ou obstáculo a ser enfrentado:

Então é isso, estou no final do meu curso na UnB, com um planejamento feito pros meus próximos passos após a graduação e me deparo com um muro, que à primeira vista me parecia intransponível, a quarentena [...] E na disciplina que eu menos esperava algo produtivo fui surpreendido, estava realmente empolgado com uma matéria de estágio, que todos meus veteranos diziam ser algo chato e extremamente burocrático e quando eu tive minha primeira experiência infelizmente tive que concordar com eles. Mas dessa vez, a professora me proporcionou espaço, opinião e deixou a burocracia de uma forma mais leve e em segundo plano, o que me deixou bem feliz (Hudá, diário de campo).

A realidade dos alunos de música no contexto do DF são muitas e plurais. Desta forma, todos os envolvidos no projeto (professora orientadora/investigadora, professor do campo e estagiários) discutimos juntos ações pedagógico-musicais possíveis que pudessem estimular o fazer musical em situações cotidianas aos alunos do CEF Jataí durante o ERE, mas que pudessem, também, oportunizar uma riqueza de experiências formativas para os estagiários, afinal partimos da perspectiva que a aula de música deveria ser um encontro positivo e significativo para todos. Assim, a burocracia foi suavi- 
zada, envolvendo os alunos em ações pautadas em metas que, para concretizá-las, eles pesquisavam na literatura e nos referenciais musicais as melhores ações e estratégias. Percebe-se que essa forma de mediação propiciou a troca de percepções, o respeito pelas opiniões de todos os envolvidos, os conhecimentos, as preferências e ideias entre os alunos com a interação tecnológica e abriram espaços para a produção de estratégias de aprendizagem. Esta experiência trouxe à tona a formação da docência atenta à realidade da escola e dialogou com os problemas e dilemas de ser músico e professor na atualidade, como reflete João Paulo:

\begin{abstract}
Paulo Freire nos ensina que tanto professores como alunos, acabam assumindo-se como sujeitos da produção do saber, assim me convencendo definitivamente de que ensinar não é transferir conhecimento, mas criar as possibilidades para a produção ou construção social do aluno, e isso mesmo que indiretamente, eu acredito ter alcançado ao longo desses meses de estágio. O que eu levo de aprendizado comigo sobre essa experiência, é que, o professor tem que ser um ser adaptativo e pronto para vencer qualquer barreira por mais inusitada que ela seja (João Paulo, memorial formativo).
\end{abstract}

A aprendizagem no estágio supervisionado torna-se mais significativa quando motivamos os alunos para aprender, quando eles estabelecem sentidos ao fazer docente, quando os engajamos em projetos colaborativos e estabelecemos diálogo, reflexão e trazemos estratégias para sua realização (CERNEV, 2015). O desenvolvimento da aprendizagem colaborativa na perspectiva aqui discutida revela, portanto, as potencialidades para que professores desenvolvam estratégias reais e possíveis com o uso das tecnologias digitais nas aulas de música de acordo com sua realidade pedagógica e com a realidade dos alunos. Sabemos que a pandemia aumentou as desigualdades sociais, infelizmente, mas também tem mostrado caminhos para a conectividade e união de situações e momentos até então impensáveis para a educação. O que precisamos agora é minimizar as rachaduras, consertar os impactos gerados e articular novas formas de produção do conhecimento. Desta forma, apresentar uma proposta em que todos pudessem contribuir e construir juntos, foi peça fundamental para aproximar os alunos à aprendizagem e à confiança entre os pares, conhecer as potencialidades de cada um, destacar e valorizar cada ação desenvolvida e sugerida. Foi uma experiência contínua de (des)construção de saberes, ampliando percepções e pontos de vista em relação aos caminhos e possibilidades que o ensino de música pode tornar:

Este semestre me trouxe experiências incriveis, poder entender como funciona a produção de um material didático me trouxe novas perspectivas enquanto profissional da música e professor. Pude entender que o mais importante na arte de lecionar e se tornar professor é analisar e entender cada circunstância para tomar a melhor decisão que ofereça aos seus alunos a melhor opção de ensino. Além disso pude presenciar na prática sobre a importância do trabalho em grupo e o cumprimento dos prazos para o bom funcionamento da aprendizagem colaborativa e tudo ser entregue de acordo com os combinados. Em meio a pandemia, no ano que vai entrar na história, conseguimos desenvolver um exemplar trabalho todos dentro de suas casas e distantes. Finalizo citando uma [frase] do 
meu poeta favorito, que explicita bem e tem relação com o nosso trabalho em confinamento: 'As grades nunca vão prender nosso pensamento, mano'- Mano Brown (Samuel, memorial formativo).

No fim, esse semestre teve um grande impacto positivo na minha formação como professor de música. Foram incentivadas o uso de plataformas alternativas para o auxílio do ensino e tivemos a nossa maleabilidade como alunos e professores posta a prova. $\mathrm{E}$, como ao fim de cada jornada, acredito que colecionamos aprendizados nos mais diversos universos: técnico, docente, social e humano (Luan, memorial formativo).

Em relação a este processo formativo e uma forma de "gravar para o futuro essa experiência", o grupo decidiu que seria importante também registrar os sentimentos despertados em todo o projeto que servirão como "referência para quando forem à realidade profissional" (Luan, mensagem WhatsApp). Desta forma, criamos um episódio final - extra do podcast "Música na Escola"7. Neste episódio que encerra o projeto, conversamos sobre as experiências oportunizadas pelo campo empírico e como a aprendizagem colaborativa se fez presente e foi fundamental para a formação destes licenciandos. Ao término do projeto, professor do campo empírico agradeceu o trabalho realizado enfatizando as potencialidades da parceria no desenvolvimento de práticas colaborativas e integradas entre Escola e Universidade:

Da minha parte foi uma grande honra e um enorme prazer termos tocado juntos esse projeto. Mais uma ação conjunta e uma oportunidade única de ter ajudado seus talentosos estudantes a conseguirem não apenas cumprir com a carga horária do estágio obrigatório, mas trazer música, arte e conhecimento para os alunos do CEF Jataí. (Prof. Sady, mensagem WhatsApp).

\section{Considerações finais}

O estagiário supervisionado é parte fundamental na configuração da profissionalização de um curso de licenciatura. Com o professor formador e o professor supervisor do estágio, vivencia-se no ambiente pedagógico da escola a realidade social aos quais são extraídos conhecimentos que influenciam diretamente na percepção do trabalho docente em música. O cenário ocasionado pelo período de isolamento social e a adaptação educacional para um ensino remoto emergencial apontou a complexidade do papel do professor para os dias atuais. Novos cenários clamam por novos caminhos para a aprendizagem musical nos contextos escolares que despertem alegria, engajamento, suporte e aproximações musicais coesas e pautadas na formação social, cultural e humana dos estudantes. Desta forma, a atuação entre Escola e Universidade por meio da parceria entre professores, licenciandos e estudantes do campo empírico tornam o fazer musical múltiplo e intenso, oportunizando trocas e aprendizagens indescritiveis para todos.

7 Link spotfy do último episódio: https://open.spotify.com/episode/OamwNV9kjkJUABUgLeMjL9?si= MjESBbE5SVOLcqr9hOBEHQ\&dl_branch=1 
Para a reflexão da formação da docência pelo estágio supervisionado em música, a criação e elaboração de um material didático no formato virtual foi extremamente relevante para discutirmos a profissionalização dentro da realidade do ERE, refletindo, conhecendo e procurando potencialidades que despertassem vivências musicais na realidade proposta. Também, a vivência na criação, implementação e acompanhamento por meio do projeto "Música na Escola" junto ao CEF Jataí, trouxe à tona a importância de desenvolvermos as habilidades individuais e coletivas dos alunos do ensino superior que podem atuar de acordo com seus interesses e conhecimentos adquirido num projeto coeso e motivador. A escolha deste método contribuiu para a construção colaborativa de uma proposta educacional pautada na identificação, elaboração, realização, atuação, reflexão e compreensão sobre a prática do estágio docente no formato remoto. De igual modo, propiciou a reflexão tanto da minha prática no papel de professora orientadora quanto do professor que recebeu os estagiários.

Pensando na formação de professores e no mercado de trabalho do músico e do professor de música, vemos a importância de criarmos, mais do que nunca, trabalhos e projetos colaborativos. Penso que, como agentes formadores de professores, é fundamental desenvolvermos nas nossas práticas processos horizontais de formação-ação, baseado na reconstrução de caminhos e saberes pedagógicos que são construídos, sistematizados, difundidos e compartilhados entre todos. O foco está no processo de construção do conhecimento, nas reflexões trazidas ao longo deste processo e, por fim, no resultado reflexivo de toda a aprendizagem desenvolvida e compartilhada. Percebe-se que essa forma de mediação propicia a troca de percepções, o respeito às opiniões dos colegas, os conhecimentos, as preferências com a interação tecnológica e abrem espaços para grupos colaborativos e para a produção de estratégias de aprendizagem pautada em metodologias ativas. Formam educadores atentos à realidade da escola e dialoga com os problemas e dilemas de ser músico e professor na atualidade.

A experiência do ESM no contexto remoto vivenciada de forma reflexiva, colaborativa e criticamente fundamentada, demonstrou na prática que, em meio às diversidades enfrentadas, o licenciando é capaz de buscar alternativas e novos propósitos para sua formação profissional. Ainda, a aprendizagem da docência se revelou para além da compreensão teórica, adentrando as paredes virtuais da sala de aula, aproximando os licenciandos em muitas situações reais que irão atuar futuramente. Os memoriais formativos apresentados por esses acadêmicos revelaram as inquietações, descobertas e incertezas de ser professor de música na contemporaneidade, mas a certeza unânime de que é possível sempre buscar novas soluções, num movimento de constante de reflexão-ação-colaboração. 


\section{Referências}

ABDULLAH, Mohd Hassan; SULONG, Mohd Azam ; RAHIM, Mahayuddin Abdul. Development and Validation of the Music Education Teaching Practice E-Supervision System Using the Google Classroom Application. International Journal of Innovation, Creativity and Change. v. 11, n. 10, p. 102- 116, 2020.

ALLSOPP, David H.; DeMARIE, Darlene; ALVAREZ-McHATTON, Patricia; DOONE, Elizabeth. Bridging the Gap between Theory and Practice: Connecting Courses with Field Experiences. Teacher Education Quarterly, v. 33, n. 1, p. 19-35, 2006.

ALTET, Marguerite. As competências do professor profissional: Entre conhecimentos, esquemas de ação e adaptação, saber analisar. In: PAQUAY, Léopold.; PERRENOUD, Philippe.; ALTET, Marguerite; CHARLIER, Évelyne (Orgs.). Formando professores profissionais. Quais estratégias? Quais competências? (2 a ed.). Porto Alegre, Brasil: Artmed, 2001. (p. 23-35).

BIESTA, Gert. Teaching for the possibility of being taught: World-centred education in an age of learning. English E-Journal of the Philosophy of Education, v. 4, p. 55-69, 2019.

BONDÍA, Jorge Larrosa. Notas sobre a experiência e o saber de experiência. Rev. Bras. Educ. [online]. n. 19, p. 20-28. 2002.

BURWELL, Kim. Studio-based instrumental learning. London, UK: Ashgate, 2012.

CERNEV, Francine Kemmer. Aprendizagem musical colaborativa mediada pelas tecnologias digitais: uma perspectiva metodológica para o ensino de música. Revista da Abem, v. 26, n. 40, p. 23-40, jan./jun. 2018.

CERNEV, Francine K. Ensino, Aprendizagem e Formação: o uso das mídias sociais pelos licenciandos de música. In: Conferência Latino-Americana De Educação Musical. Anais... Natal: ISME/ABEM, 2017a.

CERNEV, Francine K. O uso de blogs para Aprendizagem Musical no Ensino Superior: uma proposta de ensino híbrido com alunos da pedagogia. In: Congresso Nacional da Associação Brasileira de Educação Musical, Anais... Manaus: ABEM, 2017b.

CERNEV, Francine K. Aprendizagem musical colaborativa mediada pelas tecnologias digitais: estratégias de aprendizagem e motivação dos alunos. 2015. Tese (Doutorado em Música). Universidade Federal do Rio Grande do Sul, Porto Alegre, 2015. 
CERNEV, Francine K. Aprendizagem Colaborativa mediada pelas Tecnologias Digitais: um estudo realizado nas aulas de música no contexto da educação básica. Hipertextus Revista Digital (UFPE), v. 10, p. 1-17, 2013.

$\mathrm{CREECH}$, Andrea; GAUNT, Helena. The changing face of individual instrumental tuition: Value, purpose and potential. In MCPHERSON, Gary, WELCH, Graham. (Eds). Oxford handbook of music education. Oxford, UK: Oxford University Press, 2012. (p. 694-711).

CURADO SILVA, Kátia A. Epistemologia da Práxis na formação de Professores: perspectiva crítico emancipadora. Revista de ciências humanas, v. 18, n. 2, 2017.

De BRUIN, Leon R. The use of cognitive apprenticeship in the learning and teaching of improvisation: Teacher and student perspectives. Research Studies in Music Education, v. 41, n. 3, p. 261-279, 2019.

GARVEY, Bob; STOKES, Paul MEGGINSON, David. Coaching and mentoring: theory and practice. London, UK: Sage, 2009.

GAULKE, Tamar G. Aprendizagem da docência: um estudo com professores de música da educação básica. Revista da Abem, v. 21, n. 31, p. 91-104, 2013.

GONZALEZ, T., de La RUBIA, M., HINCZ, K.; LOPEZ, M.C.; SUBIRATS, L.; FORT, S. et al. Influence of COVID-19 confinement on students' performance in higher education. Plos One, 2020. Disponível em: https://doi.org/10.35542/osf.io/9zuac. Acesso em: 24/05/2021.

HONIGSFELD, Andrea; NORDMEYER, Jon. Teacher Collaboration During a Global Pandemic. An Educational Leadership Special Report, v. 77, p. 47-50, 2020.

JARDIM, Vanessa S.; MARINS, Paulo R. A. Interações Musicais via Webconferências no Curso de Licenciatura em Música a Distância da UnB. Revista da Abem, v. 27, p. 113, 2019.

KEMMIS, Stephen; McTAGGART, Robin. Participatory Action Research: communicative action and the public sphere. In: DENZIN, Norman K.; LINCOLN, Yvonna S. (Eds.). The Sage handbook of qualitative research. (3ed.), 2005. (p. 559-603).

MORAN, José Manuel. Ensino e aprendizagem inovadores com tecnologias audiovisuais e telemáticas. In: MORAN, José Manuel; MASETTO, Marcos, BEHRENS, Marilda. Novas tecnologias e mediação pedagógica. (21 ed.). São Paulo: Papirus, 2013.

MORIN, André. Pesquisa-ação integral e sistêmica: uma antropedagogia renovada. Trad. Michel Thiollent. Rio de Janeiro: DP\&A, 2004. 
SALES, Thiago; BELTRAME, Juciane A.; BATISTA, Carlos Eduardo F. AVAMUSIC: aplicação web voltada para o ensino de instrumento musical. Brazilian Journal of Development, v. 7, p. 4649-4663, 2021.

SANTANA, Myllene A. J. Contruindo a aprendizagem da docência em Música: um estudo com narrativas de um professor de música do IFB-CSAM. Trabalho de Conclusão de Curso (Graduação em Música). Universidade de Brasília, 2020.

SHIOZAWA, Priscilla; PROTÁSIO, Nilcéia. O estágio supervisionado na licenciatura em música e o desenvolvimento da autonomia. InterMeio: Revista do Programa de PósGraduação em Educação, Campo Grande, MS, v. 23, n. 45, p. 125-144, jan./jun. 2017.

TARDIF, Maurice. A profissionalização do ensino passados trinta anos: dois passos para frente, três para trás. Educação \& Sociedade, v. 34, n. 123, p. 551-571, 2013.

TORRES, Patrícia L.; ILARA, Esrom A. F. Aprendizagem colaborativa: teoria e prática. In: TORRES, Patrícia Lupion. (Org.). Complexidade: Redes e Conexões na Produção do Conhecimento. Curitiba: SENARPR, 2014, (p. 61-93).

TORRES, Patrícia L.; LOPES, Jéssica K. P.: CAMARGO, Rafael A. Aprendizagem Colaborativa e Cartografia Cognitiva: formação de professores do programa agrinho com base no pensamento complexo. Revista Docência e Cibercultura, v.5, n.1, p. 272293, 2021.

VALENTE, José Armando. A sala de aula invertida e a possibilidade do ensino personalizado: uma experiência com a graduação em midialogia. In: BACHIC, Lilian; MORAN, José Manuel. Metodologias Ativas para uma Educação Inovadora: uma abordagem teórico-prática. Penso Editora Ltda., 2018. 